\title{
Dyslipidemia in Iranian overweight and obese children
}

This article was published in the following Dove Press journal:

Therapeutics and Clinical Risk Management

17 Septmber 2009

Number of times this article has been viewed

\section{Robabeh Ghergerehchi \\ Department of Pediatrics, Tabriz University (Medical Sciences), \\ Tabriz, Iran}

Correspondence: R Ghergerehchi Department of Pediatrics, Tabriz University (Medical Sciences), Tabriz, Iran Email ghergherehchir@yahoo.com
Objective: To evaluate the frequency and patterns of dyslipidemia in overweight and obese children and to determine the extent of blood lipid abnormality in overweight and obese children.

Methods: A prospective matched case control study on 230 overweight and obese children and adolescents (body mass index [BMI] $>85$ th percentile) aged 4 to 18 years undertaken at the outpatient endocrine clinic of the Childrens' Hospital at Tabriz University between 2006-2008. This study was conducted to compare the frequency of abnormal plasma lipid levels in overweight and obese children compared with 50 nonobese children (BMI $=50$ th-85th percentile).

Results: The total frequency of dyslipidemia was $69.58 \%$. The prevalence of dyslipidemia increased with severity of obesity and reached $76.9 \%$ in the severely obese $(P<0.005)$. High triglycerides was the most common dyslipidemia in combination $(26.08 \%)$ and in isolation (18.6\%). There was a significant difference in mean of triglycerides between the severely obese and other groups $(P<0.004)$.

Conclusion: In the present study, dyslipidemia is more common in severely obese children and the most common component of dyslipidemia is a high triglyceride level.

Keywords: dyslipidemia, lipid profile, obesity, overweight, children, adolescents

\section{Introduction}

Obesity is increasing in both children and adults in many countries around the world..$^{1-4}$ A paradox of childhood underweight/overweight exists among children and adolescents living in Asian countries. However, the global problem of childhood obesity increasingly extends into the developing world. In Thailand, the prevalence of obesity among schoolchildren aged $6-12$ years rose from $12.2 \%$ to $15.6 \%$ in just two years. ${ }^{5}$ In Japan, the prevalence of obesity among schoolchildren aged 6-14 years increased from 5\% to $10 \%$ between 1974 and $1993 .{ }^{6}$ In Iran the prevalence of overweight youths aged 6-18 years doubled from $4.2 \%$ to $8.3 \%$ between 1993 and $1999 .{ }^{7}$ Associated with the epidemic of obesity in young people is an epidemic of medical complications such as dyslipidemia, hypertension, and type 2 diabetes mellitus. One morbidity associated with obesity is cardiovascular disease which is invariably related to dyslipidemia. ${ }^{8}$ It is now well established that the atherosclerotic process and cardiovascular disease begins in youth and is significantly related to lipid abnormalities. ${ }^{9-11}$ The dyslipidemia associated with obesity is characterized by a triad of lipid abnormalities, including elevated serum triglycerides (TG), the presence of small, dense low-density lipoprotein (LDL) particles and reduced serum high-density lipoprotein cholesterol (HDL-C) levels. ${ }^{12}$ Pathologic studies, such as the Bogalusa Heart 
Study, and the pathological determination of atherosclerosis in youth (PDAY) study, have shown that higher levels of LDL-cholesterol (LDL-C) are significantly related to increased areas of the aorta and coronary arteries involved with fatty streaks and fibrous plaques. ${ }^{13}$ The early detection of dyslipidemia in obese children and adolescents may help to delay or prevent chronic complications. In this regard the aim of the present study was to evaluate the frequency and patterns of dyslipidemia in obese children and adolescents and to determine the extent of blood lipid abnormality in overweight and obese children.

\section{Patients and methods}

\section{Study population}

A matched case control study was conducted on overweight and obese children and adolescents, who were referred to the Children's Hospital in Tabriz, Iran, from September 2006 through to October 2008.

We investigated a sample of 230 overweight and obese children and adolescents. Patients were selected according to the following inclusion criteria: aged between 4 to 18 years and a body mass index (BMI) exceeding the 85 th percentile for their age and sex.

\section{Exclusion criteria}

Patients with familial hyperlipidemia, obesity secondary to genetic disorders, hypothyroidism, and who were using medication that alters lipid metabolism, were excluded.

Fifty nonobese children were recruited as a comparison control group. These patients were clinically evaluated by a physician. The following inclusion criteria were used for the control group: BMI 50th-85th percentile and absence of chronic diseases (liver, renal, thyroid). Patients in the control groups were age- and sex-matched with more than one patient. The local ethical committee approved the study and informed consent was obtained from the patients.

\section{Anthropometric and metabolic variables}

Demographic variables examined were age and sex. Anthropometric variables included weight, height, and BMI. To standardize BMI levels, conversion to a BMI Z-score was performed based on the Centers for Disease Control and Prevention growth charts. ${ }^{14}$ The case subjects were then classified as overweight (a $Z$-score of 1 to 2 ), moderately obese (a $Z$-score of 2 to 2.5 ), and severely obese (a $Z$-score above 2.5). Metabolic parameters were total cholesterol (TC), TG, HDL-C, and LDL-C.

\section{Biochemical analysis}

Blood samples were obtained after a 12-hour overnight fast for measurement of TC, HDL-C, LDL-C, and TGs. Lipid levels were measured with the use of an autoanalyzer (model 200-747; Hitachi, Dubai, Saudi Arabia). Dyslipidemia was defined if the fasting plasma HDL-C was less than the 5th percentile or TGs, LDL-C, and TC were greater than the 95th percentile for age and sex. ${ }^{15}$

\section{Statistical analysis}

Data was expressed as mean \pm standard deviation (SD) number percentage. These were analyzed with the independent samples $t$-test, analysis of variance, Tukey's test and Kendall's tau-b correlation coefficient for TC, LDL, HDL, and TG between groups.

A $P$ value less than 0.05 was considered statistically significant. The Statistics Package for Social Sciences (version 16; SPSS Inc., Chicago, IL, USA) was used for statistical analysis.

\section{Results}

Of 230 (94 male and 136 female) overweight and obese children and adolescents included in this study, 117 (50.9\%) were severely obese, $41(17.8 \%)$ were moderately obese, and $72(31.3 \%)$ were overweight. With regard to their ages, $43(18.7 \%)$ of cases were of school age, 98 (42.6\%) were preadolescent, and $89(38.7 \%)$ were adolescents.

The mean values of age, weight, height, and BMI is provided in Table 1. BMI was statistically different between the overweight and obesity groups, compared to the control group $(P<0.005)$. Table 2 shows the comparison of mean \pm SD for lipid values by degree of obesity and sex. There was a significant difference for means of triglycerides between the severely obese and other groups $(P<0.004)$. LDL-C in the severely obese group was significantly higher than in the normal group $(P<0.005)$. There was a significant difference of mean HDL-C and TC between the overweight and obese groups compared to the control group $(P<0.005)$.

The overall incidence of dyslipidemia was $69.58 \%$ $(n=160), 56.8 \%(n=90)$ in the severely obese, $16.9 \%$ $(n=27)$ in the moderately obese, and $26.2 \%(n=42)$ in the overweight. No one in the control group had dyslipidemia. According to the age incidence of dyslipidemia, there was $62.8 \%(n=27)$ of school age, $73.5 \%(n=72)$ preadolescents, and $67.4 \%(n=60)$ in adolescents, but no statistical difference was observed. The prevalence of the dyslipidemia increased significantly as the BMI increased $(P<0.005$, $\left.\mathrm{df}=5, \chi^{2}=86.48\right)$. 
Table I General characteristics of the overweight, obese, and control groups

\begin{tabular}{|c|c|c|c|c|c|c|c|c|}
\hline \multirow{2}{*}{$\begin{array}{l}\text { General } \\
\text { characteristics }\end{array}$} & \multicolumn{2}{|c|}{ Severe obesity } & \multicolumn{2}{|c|}{ Moderate obesity } & \multicolumn{2}{|l|}{ Overweight } & \multicolumn{2}{|l|}{ Control } \\
\hline & $\begin{array}{l}\text { Male } \\
(n=55)\end{array}$ & $\begin{array}{l}\text { Female } \\
(n=62)\end{array}$ & $\begin{array}{l}\text { Male } \\
(n=12)\end{array}$ & $\begin{array}{l}\text { Female } \\
(n=29)\end{array}$ & $\begin{array}{l}\text { Male } \\
(n=27)\end{array}$ & $\begin{array}{l}\text { Female } \\
(n=45)\end{array}$ & $\begin{array}{l}\text { Male } \\
(n=29)\end{array}$ & $\begin{array}{l}\text { Female } \\
(n=2 I)\end{array}$ \\
\hline Age (years) & $10.2 \pm 3.2$ & $8.4 \pm 3.0$ & $11.8 \pm 2.5$ & $10.9 \pm 3.1$ & $12.3 \pm 2.0$ & $1 \mathrm{I} .2 \pm 2.4$ & $109 . \pm 4.1$ & $10.3 \pm 4.8$ \\
\hline Weight (kg) & $65.7 \pm 23.5$ & $53.7 \pm 20.1$ & $61.6 \pm 11.1$ & $56.7 \pm 17.7$ & $54.7 \pm 11.2$ & $51.0 \pm 12.0$ & $36.0 \pm 13.0$ & $34.2 \pm 15.1$ \\
\hline Height (cm) & $143.0 \pm 18.2$ & $133.5 \pm 14.7$ & $148.5 \pm 15.2$ & $142.1 \pm 12.4$ & $147.8 \pm 11.9$ & $143.3 \pm 10.2$ & $138.8 \pm 17.1$ & $134.3 \pm 21.6$ \\
\hline BMI $\left(\mathrm{kg} / \mathrm{m}^{2}\right)$ & $30.9 \pm 5.5$ & $29.1 \pm 5.7$ & $27.2 \pm 2.7$ & $27.9 \pm 4.2$ & $24.7 \pm 1.9$ & $24.4 \pm 2.5$ & $17.8 \pm 2.7$ & $17.8 \pm 3.0$ \\
\hline
\end{tabular}

Note: Mean \pm standard deviation.

Abbreviation: BMI, body mass index.

There was a positive correlation $(\mathrm{r}=0.226 ; P<0.0001)$ between $\mathrm{BMI}$ and triglycerides and a negative correlation ( $\mathrm{r}=0.255 ; P<0.0001)$ between BMI and HDL-C, with a significant correlation found between BMI and LDL-C ( $\mathrm{r}=0.96 ; P=0.05)$.

Table 3 shows that the most common component of dyslipidemia in combination (26.08\%) and in isolation (18.6\%) was high TGs. Low HDL-C was the second component of lipid abnormality, whereas the combination of high TG and low HDL-C was observed in $8.3 \%$ of participants. All four components of the disorder were found in $3.5 \%$ of participants $(n=8)$. No statistical difference was observed within the groups according to sex and age.

\section{Discussion}

The findings in this study reveal a high prevalence of dyslipidemia in overweight and obese children and adolescents, regardless of age and sex. Approximately $50 \%$ of severe obese children and third of overweight children have dyslipidemia, which is higher than the overall youth population of the Bogalusa Heart Study. ${ }^{10}$ The combination of obesity and dyslipidemia has an additive effect of increasing the severity of atherosclerotic lesions in young people. ${ }^{16}$ Elevated LDL-C and BMI levels are also predictive of carodid intima-media thickness in adolescents, which is strongly associated with coronary atherosclerosis and cardiovascular risk. The rate of dyslipidemia according to our criteria was greater than the rate reported by Cook and colleagues, ${ }^{17}$ but the results of our analyses are consistent with reports by Gillian and colleagues..$^{18}$ The degree of obesity in children and adolescents has important clinical implications because the risk of death from all causes among adults with severe obesity is twice that than among moderately obese adults. ${ }^{19}$ Our study shows that, as with obese adults, high TG is the most common component. Moreover the mean TG concentration rises with increasing obesity $(P<0.004)$ which is consistent with the findings of Lima and colleagues. ${ }^{20}$

The second component of the lipid abnormality was related to decreased levels of HDL-C. Hepatic triglyceride lipase catabolizes the TGs, resulting in a reduction in HDL particle size and an increase in HDL-C clearance, which leads a decrease in HDL-C levels. Many epidemiologic studies have demonstrated that low HDL-C levels are an independent risk factor for cardiovascular disease. ${ }^{18} \mathrm{HDL}-\mathrm{C}$, which acts as protective factor against heart disease, ${ }^{21}$ showed borderline values in our study children, with slightly higher

Table 2 Lipid profile of the children and adolescents of the obesity, overweight, and control groups

\begin{tabular}{|c|c|c|c|c|c|c|c|c|}
\hline \multirow[t]{2}{*}{ Lipid profile } & \multicolumn{2}{|c|}{ Severely obese } & \multicolumn{2}{|c|}{ Moderately obese } & \multicolumn{2}{|l|}{ Overweight } & \multicolumn{2}{|l|}{ Control } \\
\hline & $\begin{array}{l}\text { Male } \\
(n=55)\end{array}$ & $\begin{array}{l}\text { Female } \\
(n=62)\end{array}$ & $\begin{array}{l}\text { Male } \\
(n=12)\end{array}$ & $\begin{array}{l}\text { Female } \\
(n=29)\end{array}$ & $\begin{array}{l}\text { Male } \\
(n=27)\end{array}$ & $\begin{array}{l}\text { Female } \\
(n=45)\end{array}$ & $\begin{array}{l}\text { Male } \\
(n=29)\end{array}$ & $\begin{array}{l}\text { Female } \\
(n=2 I)\end{array}$ \\
\hline $\begin{array}{l}\text { Triglycerides } \\
(\mathrm{mg} / \mathrm{dL})^{*}\end{array}$ & $179.6 \pm 30.7$ & $183.1 \pm 36.5$ & $128.7 \pm 67.1$ & $107.8 \pm 47.2$ & $99.1 \pm 34.5$ & $105.6 \pm 26.5$ & $100.4 \pm 11.1$ & $102.0 \pm 14.0$ \\
\hline $\begin{array}{l}\text { Total cholesterol } \\
(\mathrm{mg} / \mathrm{dL})^{* *}\end{array}$ & $156.8 \pm 92.6$ & $144.5 \pm 67.7$ & $163.4 \pm 31.7$ & $190.1 \pm 38.4$ & $176.3 \pm 24.3$ & $183.8 \pm 34.2$ & $122.4 \pm 11.3$ & $123.0 \pm 10.6$ \\
\hline LDL-C (mg/dL)** & $111.5 \pm 34.4$ & $113.0 \pm 34.1$ & $95.8 \pm 25.3$ & $118.6 \pm 38.9$ & $46.1 \pm 8.9$ & $42.8 \pm 9.8$ & $95.9 \pm 9.5$ & $96.8 \pm 6.2$ \\
\hline HDL-C (mg/dL)** & $41.6 \pm 10.8$ & $45.0 \pm 12.0$ & $39.1 \pm 6.2$ & $45.2 \pm 14.9$ & $104.4 \pm 24.1$ & $114.2 \pm 0.8$ & $54.0 \pm 7.2$ & $54.2 \pm 7.0$ \\
\hline
\end{tabular}

Notes: Mean \pm standard deviation; $* \mathrm{mg} / \mathrm{dL} \times 0.01125=\mathrm{nmol} / \mathrm{L} ; * * \mathrm{mg} / \mathrm{dL} \times 0.02586=\mathrm{nmol} / \mathrm{L}$.

Abbreviations: HDL-C, high-density lipoprotein cholesterol; LDL-C, low-density lipoprotein cholesterol. 
Table 3 Patterns of isolated and combination dyslipidemia

\begin{tabular}{lll}
\hline Dyslipidemia & Isolated & Any combination \\
\hline High triglycerides & $52(18.6 \%)$ & $60(26.08 \%)$ \\
Low HDL-C & $14(6 \%)$ & $39(16.96 \%)$ \\
High LDL-C & $4(1.7 \%)$ & $36(15.6 \%)$ \\
High total cholesterol & $8(3.4 \%)$ & $52(22.60 \%)$ \\
High TG + low HDL & $19(8.3 \%)$ & \\
High TG + high cholesterol & $12(5.2 \%)$ & \\
High TG + high-LDL-C & $6(2.6 \%)$ & \\
High LDL-C + high TG + & $1(0.4 \%)$ & \\
low HDL-C & \\
High TG + high cholesterol + & $5(2.2 \%)$ & \\
low HDL-C &
\end{tabular}

Abbreviations: HDL-C, high-density lipoprotein cholesterol; LDL-C, low-density lipoprotein cholesterol;TG, triglycerides.

levels than those found by Webber and colleagues ${ }^{22}$ and Lima and colleagues. ${ }^{20}$ We found 14 children and adolescents with HDL-C $<5$ th percentile for age and sex. There was a significant difference for mean HDL-C in the control group compared with the other groups.

LDL-C levels in our study were higher than those found by Moura and colleagues, ${ }^{23}$ which may be attributed to a high intake of saturated fat and to a low intake of dietary fiber. $^{24}$

The third component of lipid abnormalities was related to increased levels of total cholesterol. There was significant difference between the mean of serum total cholesterol concentration in the normal group with other the groups $(P<0.005)$. Our report is the first to describe the prevalence of dyslipidemia in overweight and obese children in northwest Iran. A limitation of this study is the possibility of selection bias because the study sample was based on patients who were referred to a weight management clinic. Children at increased risk may be more likely to be referred to a weight management program.

\section{Conclusion}

Our study demonstrated that the dyslipidemia is more common in severely obese children and adolescents, and high TGs was the most common component of dyslipidemia. We found a significant correlation between the elevation of TGs and the severity of obesity.

\section{Acknowledgments}

We thank all children and their parents for participating in our study. The author reports no conflict of interest in this work.

\section{References}

1. Troiano RP, Flegal KM, Kuczmarski RJ, et al. Overweight prevalence and trends for children national health and nutrition examination surgery. 1963 to 1991. Arch Pediatr Adolesc Med. 1995;149:1091-2085.

2. Booth ML, Dobbins T, Okely AD, Denney-Wilson E, Hardy LL. Trends in the prevalence of overweight and obesity among young Australians, 1985, 1997 and 2004. Obesity (Silver Spring). 2007;15:1089-1095.

3. Li Y, Schouten EG, Hu X, Cui Z, Luan D, Ma G. Obesity prevalence and time trend among youngsters in China, 1982-2002. Asia Pac J Clin Nutr. 2008;17:131-137.

4. Tremblay MS, Willms JD. Secular trends in the body mass index of Canadian children. CMAJ. 2000;163:1429-1433.

5. Mo-suwan L, Junjana C, Puetpaiboon A. Increasing obesity in school children in the transitional society and the effect of the weight control program. Southeast Asian J Trop Med Public Health. 1993;24: $590-594$.

6. World Health Organization. Obesity: prevention and managing the global epidemic. (WHO Technical Report Series no. 894). Geneva, Switzerland: Word Health Organization; 2000.

7. Kelishadi R, Hashemipour M, Sarraf-Zadegan N, et al. Trend of atherosclerosis risk factors in children of Isfahan. Asian Cardiovasc Thorac Ann. 2001;9:36-40.

8. Gidding SS, Bao W, Srinivasan SR, Berenson GS. Effects of secular trends in obesity on coronary risk factors in children: The Bogalusa Heart Study. J Pediatr. 1995;127:868-874.

9. Grundy SM. Hypertriylceridemia, atherogenic dyslipidemia, and the metabolic syndrome. Am J Cardiol. 1998;81:18B-25B.

10. Freedman DS, Khan LK, Dietz WH, Srinivasan SR, Berenson GS. Relationship of childhood obesity to coronary heart disease risk factors in adulthood: The Bogalusa Heart Study. Pediatrics. 2001;100:712-718.

11. Berenson GS, Srinivasan SR, Bao W, Newman WP III, Tracy RE, Wattigney WA. Association between multiple cardiovascular risk factors and atherosclerosis in children and young adults. The Bogalusa Heart Study. N Engl J Med. 1998;338:1650-1656.

12. Brinton EA. Lipid abnormalities in the metabolic syndrome. Curr Diab Rep. 2003;3:65-72.

13. Berenson GS, Srinivasan SR, Bao W, et al. Association between multiple cardiovascular risk factors and atherosclerosis in children and young adults. N Engl J Med. 1998;338:1650-1656.

14. Centers for Disease Control and Prevention. CDC Growth Charts: CDC table for calculated body mass index values for selected heights and weights for ages 2 to 20 years. 2002. Available from: http://www.cdc. gov/growthcharts. Accessed February 20, 2006.

15. Klingman RM, Behrman RE, Jenson HB, Stanton BF. Disorders of lipoprotein metabolism and transport. Nelson Textbook of Pediatrics. 2007;18:580-593.

16. Strong JP, Malcom GT, Oalmann MC, Wissler RW. The PDAY Study: natural history, risk factors, and pathobiology. Pathobiological Determinants of Atherosclerosis in Youth. Ann NY Acad Sci. 1997;811: 226-237.

17. Cook S, Weitzman M, Auinger P, Nguyen M, Dietz WH. Prevalence of a metabolic syndrome phenotype in adolescents: findings from the third National Health and Nutrition Examination Survey, 1988-1994. Arch Pediatr Adolesc Med. 2003;157:821-827.

18. Boyd GS, Koenigsberg J, Falkner B, Gidding S, Hassink S. Effect of obesity and high blood pressure on plasma lipid levels in children and adolescents. Pediatrics. 2005;116(2):442-446.

19. Calle EE, Thun MJ, Petrelli JM, Rodriguez C, Heath CW Jr. Body-mass index and mortality in a prospective cohort of US. adults. $N$ Engl J Med. 1999;341:1097-1105

20. Lima SCVC, Arrais RF, Almeida MG, Souza ZM, Pedrosa LFC. Plasma lipid profile and lipid peroxidation in overweight or obese children and adolescents. J Pediatr (Rio J). 2004;80(1):23-28.

21. Gordon DJ, Probstfield JI, Garrison RJ, et al. High-density lipoprotein cholesterol and cardiovascular disease. Four prospective American studies. Circulation. 1989;79:8-15. 
22. Webber LS, Organian V, Luepker RV, et al. Cardiovascular risk factors among third grade children in four regions of the United States. Am J Epidemiol. 1995;141:428-439.

23. Moura EC, Nakamura SY, Romero VSV. Níveis de colesterol em escolares da primeira série de uma escola pública de Campinas, São Paulo, Brasil. Rev Nutr PUCCAMP. 1997;10:63-69.
24. Gillis LJ, Kennedy LC, Gillis AM, Bar-Or O. Relationship between juvenile obesity, dietary energy and fat intake and physical activity. Int J Obes Relat Metab Disord. 2002;26(4):458-463.

Therapeutics and Clinical Risk Management

\section{Publish your work in this journal}

Therapeutics and Clinical Risk Management is an international, peerreviewed journal of clinical therapeutics and risk management, focusing on concise rapid reporting of clinical studies in all therapeutic areas, outcomes, safety, and programs for the effective, safe, and sustained use of medicines. This journal is indexed on PubMed Central, CAS,
EMBase, Scopus and the Elsevier Bibliographic databases. The manuscript management system is completely online and includes a very quick and fair peer-review system, which is all easy to use. Visit http://www.dovepress.com/testimonials.php to read real quotes from published authors.

Submit your manuscript here: http://www.dovepress.com/therapeutics-and-clinical-risk-management-journal 